\title{
Bilateral Choanal Atresia in a Teenager: Transnasal Endoscopic Approach
}

\author{
${ }^{1}$ TK Hazra, ${ }^{2}$ Saumik Das, ${ }^{3}$ Aniruddha Majumder, ${ }^{4}$ Amit Chakraborty \\ ${ }^{5}$ Mukesh Kumar Singh, ${ }^{5}$ Chiranjib Das \\ ${ }^{1}$ Professor and Head, Department of Otolaryngology, Medical College and Hospital, Kolkata, West Bengal, India \\ ${ }^{2}$ Assistant Professor, Department of Otolaryngology, Medical College and Hospital, Kolkata, West Bengal, India \\ ${ }^{3} \mathrm{RMO}$ cum Clinical Tutor, Department of Otolaryngology, Medical College and Hospital, Kolkata, West Bengal, India \\ ${ }^{4}$ Senior Resident, Department of Otolaryngology, Medical College and Hospital, Kolkata, West Bengal, India \\ ${ }^{5}$ Postgraduate Trainee, Department of Otolaryngology, Medical College and Hospital, Kolkata, West Bengal, India
}

Correspondence: Aniruddha Majumder, RMO cum Clinical Tutor, Department of Otolaryngology, Medical College and Hospital Kolkata, West Bengal, India, e-mail: dr.anirudha@yahoo.com

\section{ABSTRACT}

Congenital choanal atresia has been recognized for over 200 years, first described by Roederer in 1775 . Choanal atresia is an uncommon congenital anomaly. Choanal atresia is strongly suspected on the clinical sign and symptoms and confirmed with radiographs. CA repair in teenagers is not as common as it is in babies, but it still takes place and with good result. Transnasal endoscopic repair of CA is a safe and successful technique.

Keywords: Bilateral choanal atresia, Teenagers, Transnasal endoscopic approach.

\section{INTRODUCTION}

Choanal atresia $(\mathrm{CA})$ is a rare congenital disease which occurs in about one in 8,000 live birth and affects the females more commonly than males in the ratio of $2: 1{ }^{1}$ The condition is the most common nasal abnormality in newborn infant. CA repair in teenagers is very rare, but it still takes place with good result.

\section{CASE REPORT}

An 18-year-old male patient from Srirampur, West Bengal, India, presented with bilateral nasal obstruction with respiratory distress on exertion. He also complained of mucoid nasal discharge and headache off and on. On examination, nasal cavities were filled with thick tenacious mucoid discharge. Cold spatula test and cotton wool test were negative. Infant tube no. 10 could not be passed through the nose beyond $4 \mathrm{~cm}$. There were no other congenital anomalies detected in the body. All routine investigations were within normal limits. CT of nose and PNS axial and coronal view showed bilateral choanal atresia (Figs 1 and 2). Nasal endoscopy with $0^{\circ}$ endoscope shows bilateral almost complete atresia (small hole approximately $1 \mathrm{~mm}$ in diameter) covered with mucoid discharge (Fig. 3).

The patient underwent surgical repair of choanal atresia with transnasal endoscopic approach under general anesthesia. At first nasopharynx was palpated. On palpation, soft tissue mass was felt filling the anterior portion of nasopharynx and no bony plate or other structure could be felt. Mucosa over the bony septum was removed and bleeding controlled by using suction cautery. The posterior part of septum was removed using bone gauge and good access to the plate made. The opening was enlarged by using Kerrison punch. During the dissection, a finger was placed perorally in the nasopharynx for assessing the opening and act as a guard to protect the skull base. At the end of the procedure, a no. 7 cuffed endotracheal tube was used for

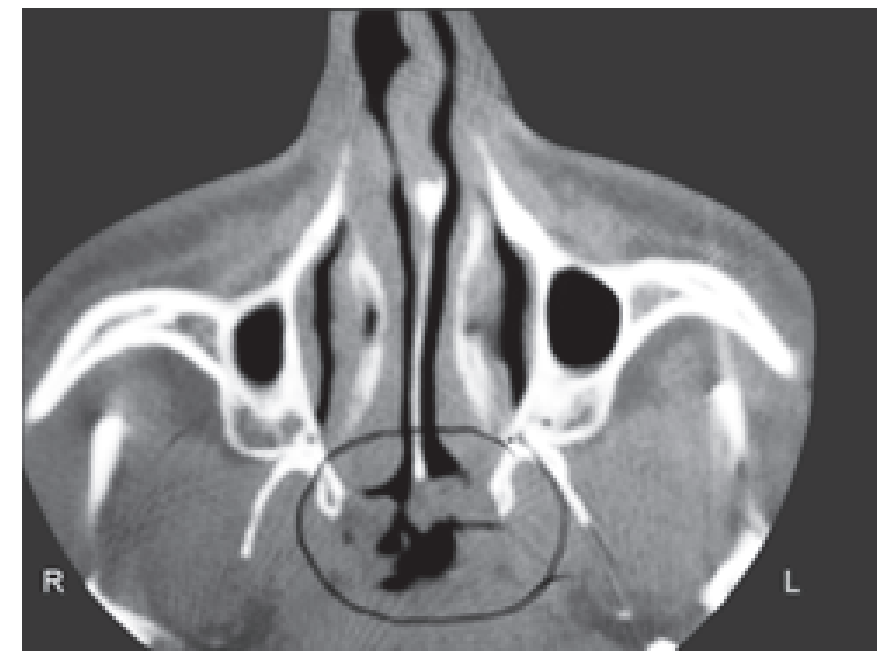

Fig. 1: CT scan-axial cuts, showing bilateral choanal atresia 


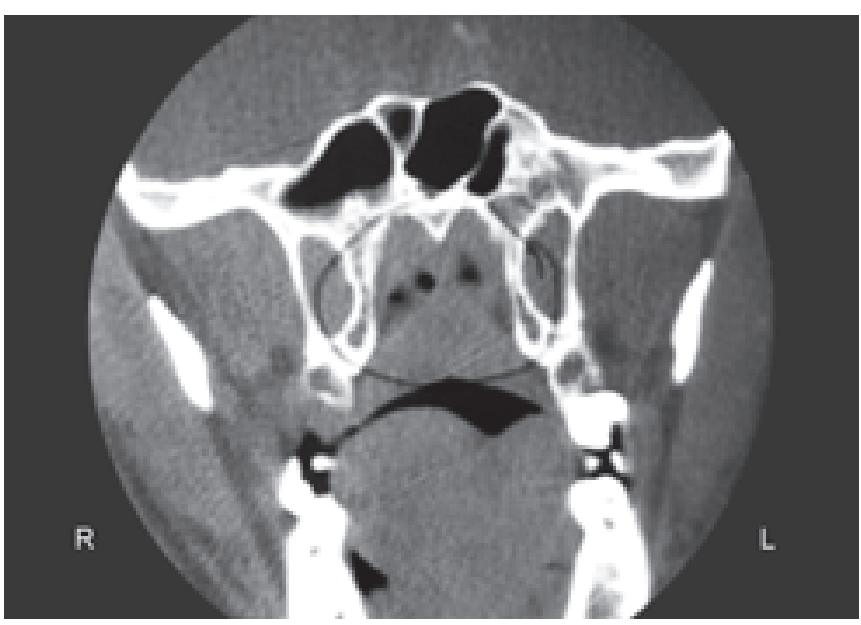

Fig. 2: Bilateral choanal atresia evident on coronal sections

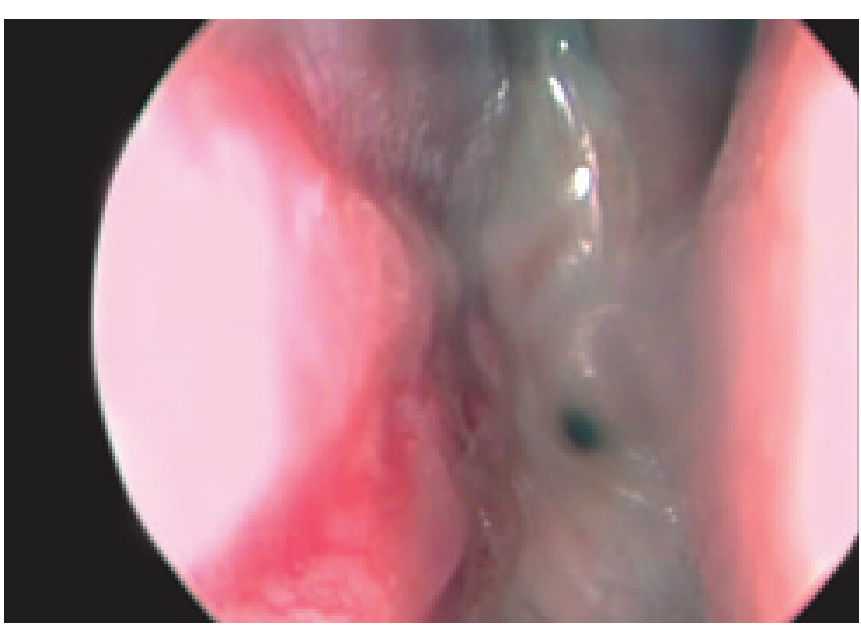

Fig. 3: Endoscopic view of choanal atresia showing a pin hole opening

stenting and kept in situ for 6 weeks (Fig. 4). Postoperative period was uneventful, and after 6 weeks stent was removed under full aseptic precaution and choanal opening was assessed endoscopically. Choanal opening was adequate, no granulation and edema were seen around the choana. The patient was followed up endoscopically every 6 weeks. After 6 months follow-up, the patient was both subjectively and objectively much improved.

\section{DISCUSSION}

$\mathrm{CA}$ is a rare congenital disease which occurs in about one in 8,000 live births and affects the females more commonly than males in the ratio of $2: 1 .{ }^{1} \mathrm{CA}$ is a narrowing or blockage of the nasal airway by tissue. Bilateral complete choanal atresia is incompatible with life as newborn human babies are obligatory nose breathers. CA may involve bone or membrane, obstruct one or both postnasal apertures may be complete or partial. ${ }^{2} \mathrm{CA}$ is of mixed type in $71 \%$ of cases while pure bone type is seen in $29 \%$ of cases and pure membranous type is not reported. ${ }^{4}$ In our case, CA is mixed type.

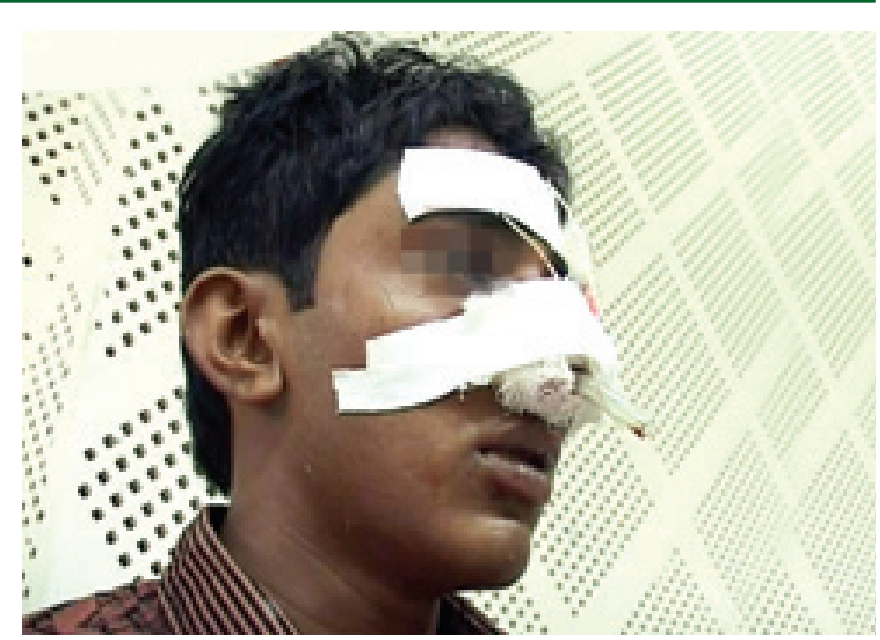

Fig. 4: Patient with stent in situ

The causes of CA are unknown. It is thought to occur when the thin tissue separating the nasal and oral spaces during fetal development remains after birth. Classic theories of embryogenesis of posterior choanal atresia implicate persistence of either the nasobuccal membrane or failure of the buccopharyngeal membrane to recanalize or the presence of adhesion in the area. ${ }^{3}$ Hengerer and Strome have proposed that neural crest cells may migrate into this area, which, if already abnormal, may alter the flow of neural crest cells. ${ }^{4}$ Bilateral partial CA usually presents with respiratory distress which is aggravated by feeding and relieved by crying in infants. In our case, the patient is a teenager and presented with respiratory distress on exertion. It is a very unusual presentation of CA in this adult age. In this case, it was not complete atresia-a small hole around $1 \mathrm{~mm}$ in diameter was bilaterally present and he could manage to breath through this hole, but in case of exertion or respiratory infection he developed respiratory distress and for that his parents repeatedly consulted physician and chest specialists.

Multisystem abnormalities are usually associated - the CHARGE syndrome (colobomatous blindness, heart diseases, atresia of the choana, retarded growth, genital hyperplasia in males, ear deformities). ${ }^{1}$ But in the present case, no other congenital abnormality was detected. CT is the current investigation of choice, while choanography had been the traditional method of investigation. ${ }^{5}$ In our case also the CT nose and PNS in axial and coronal view showed bilateral partial mixed atresia. Surgery is the treatment of choice. Recent discussions are being centered on approaches which yield best result and least morbidity. ${ }^{6}$ There are four approaches to the posterior part of nasal cavity, i.e. transnasal, transpalatal, transantral and trans-septal. Success rate with these techniques ranges from 55 to $85 \%$. ${ }^{1}$ The endoscopic transnasal repair is preferred in cases of infants and teenagers as it is quick, safe and avoids hard palate and alveolar arch growth retardation. Recent advances in endonasal endoscopic surgery have opened the way for endoscopic transnasal repair of CA as it provides excellent 
visualization of nasal cavity and posterior choana. The success rate of transnasal endoscopic technique is up to $100 \% .^{2}$ In the present case with the transnasal approach choanal opening made with Kerrison punch and stented for 6 weeks with cuffed endotracheal tube and we had good result with stenting. After removal of stent in subsequent follow-up, the patient was symptom free. However, the key to success with the transnasal approach is dependent on the following factors, like prevention of excessive granulation tissue formation achieved by prevention of excessive damage or removal of mucosa, use of soft polyvinyl portex tube and use of broad spectrum antibiotic, and following the procedure choana must be stented for a period of at least 6 weeks. In our case, patient is teenager, and in teenage, bilateral choanal atresia is very rare and this makes the case interesting.

\section{REFERENCES}

1. Michael JC. Congenital anomalies of the nose. Scott Brown's Pediatric Otolaryngology (6th ed). Oxford ButterworthHeinemann 1997: p,6/15/2-6/15/5.

2. Shivakumar AM, Ashok SN, Praveen DS. Choanal atresia: Experience with transnasal endoscopic technique. Indian Journal of Otolaryngology and Head and Neck surgery 2005;57(2): 96-98.

3. Bergstrom L, Owens O. Posterior choanal atresia: A syndromal disorder. Laryngoscope 1984;94:127-26.

4. Hengener AS, Strome H. Choanal atresia. Laryngoscope 1982; 92: 913-22.

5. Crockett DM, Healy GB, McGullt J. Computed tomography in the evaluation of choanal atresia in infants and children. Laryngoscope 1997;97:174-83.

6. Schwartz ML, Savetsky L. Choanal atresia: Clinical features, surgical approach and long-term follow-up. Laryngoscope 1986;96:1335-39. 